\title{
Evaluation on the Effect of Service-Learning in E- Business Professional Curriculum
}

\author{
https://doi.org/10.3991/ijet.v14i08.10403 \\ Jie Ji \\ Yangzhou Polytechnic College, Yang Zhou, China \\ Jianqiang $\mathrm{Gu}\left({ }^{\square}\right)$ \\ Yangzhou University, Yang Zhou, China \\ gujiangiang@yzu.edu.cn
}

\begin{abstract}
Based on structural equation model, this paper evaluated the effect of Service-Learning in E-business professional curriculum, and built a structural equation model of Service-Learning and its influencing factors from three aspects: project resource, teaching organization and student engagement, in order to understand the students' satisfaction to the effect of ServiceLearning and the relevant factors. The results show that, the effect of ServiceLearning is influenced by the three aspects mentioned above. Among which, teaching organization and student engagement have a direct effect on the effect of Service-Learning; however, the influence of the project resource mainly displays the indirect influence.
\end{abstract}

Keywords - Service-Learning; structural equation model; teaching results; Ebusiness professional curriculum

\section{Introduction}

Service learning is a teaching method with rich contents and forms, which helps students effectively link individual abilities and practice results. In the past dozens of years, the scientific field of service learning applications has begun to diversify, covering education professions and nursing professions to almost all disciplines ${ }^{[1]}$. Under the new service learning paradigm, students use the knowledge and theory learned in school on the one hand, and closely combine learning with social practice on the other hand, thus dealing with problems in real situations. In this process, knowledge and skills are upgraded ${ }^{[2]}$. Service learning in colleges and universities in China has become a popular teaching model that has been widely promoted, but measurement of its teaching effect is a complicated task. The reason is that the main body involved in educational process of service learning is diversified, including teachers, students and social institutions. Any link will create a complicated mechanism of action on teaching result, and many factors cannot be directly measured by traditional statistical methods. These have deepened the difficulty of evaluation ${ }^{[3]}$. Therefore, taking teaching evaluation of e-commerce service learning as an example 
to analyze factors influencing teaching result and explore effective ways to improve teaching result of service learning is a very meaningful work. This paper theoretically constructs the influencing factor model of service learning effect in e-commerce professional course, and conducts empirical analysis through structural equation model with a view to providing targeted and feasible teaching suggestions.

\section{Research Hypothesis}

So far, a large number of literatures in the academic world have explored the influencing factors of service learning teaching result from different perspectives. $\mathrm{Li}$ Chuan and Li Lingling (2015) believed that in the process of designing and developing service learning projects, teachers need provide guidance, refine learning objectives, and deepen students' understanding and application of classroom knowledge in the service process ${ }^{[4]}$. Guan Xuan (2017) believed that integration of curriculum and service learning contents through curriculum design, and focus on overall planning and links of the curriculum are successful experiences of service learning in public universities in Hong Kong ${ }^{[5]}$. Zhang Lijun (2018) held that service learning teaching result is affected by characteristics of the service project itself and design contents of the program. Not only that, in the service learning process, teachers should instruct students to solve the difficulties and problems encountered in the service learning practice ${ }^{[6]}$. Through years of experience in service learning teaching and continuous follow-up investigation of students for several years, as well as interviews with front-line teachers engaged in e-commerce service learning, this paper summarizes the factors influencing e-commerce learning effects as project resource, teaching organization, and student engagement.

\subsection{Project resource}

The intrinsic characteristics of project resource are the key to teaching of service learning ${ }^{[7]}$. The projects selected for service learning should have strong professionality and characteristic e-commerce backgrounds. Quality of service learning program is the cornerstone for service learning curriculum development and curriculum design. It provides a good practice platform for students to improve their skills. Therefore, this paper adopts professional relevance of the program, practice environment of the program and cooperation degree of program participants to measure the effect of project resource on curriculum design and teaching result. On this basis, this paper proposes hypotheses $\mathrm{H} 1, \mathrm{H} 2$, and $\mathrm{H} 3$.

- H1: Project resource has a significant positive impact on teaching organization.

- H2: Project resource has a significant positive impact on student engagement.

- H3: Project resource has a significant positive impact on teaching result. 


\subsection{Teaching organization}

The e-commerce service learning curriculum design is different from general curriculum design, which needs provision of networked project environment and office conditions as well as certain business demands. Centered around the new teaching model of service learning, curriculum design is to explore curriculum system design combining curriculum and service projects. Obeying professional characteristics, teachers closely combine project process with theoretical curriculum in talent training program in accordance with practical teaching needs of the project, effectively formulate teaching strategies, organize learning contents and arrange teaching links ${ }^{[8]}$. Therefore, this paper uses curriculum progress design, theoretical embedded design, student participation mechanism design and teacher curriculum control system design to measure the influence of teaching organization on teaching result. Based on this, this paper proposes the hypotheses $\mathrm{H} 4, \mathrm{H} 5$.

- H4:Teaching organization has a significant positive impact on teaching result

- H5:Teaching organization has a significant positive impact on student engagement

\subsection{Student engagement}

The service learning teaching model subverts the definition of time and space in traditional classrooms, and transforms the structure and model of cramming passive learning system in traditional education ${ }^{[10]}$. Passive acceptance of students is transformed into learning through service, which gives greater freedom of time and space for students to acquire knowledge, and promotes the transformation of teaching methods. Service learning requires students to have enthusiasm, creativity, cooperation and self-learning ability. Curriculum implementation stresses the transition from "requiring students to learn" to "student wants to learn", so that students increase participation, actively explore learning, and enhance group cooperation ability ${ }^{[11]}$. Therefore, this paper adopts student adaptability, student comprehension, student effort and student cooperation to measure the impact of student engagement on teaching result. On this basis, this paper proposes the hypothesis H6.

- H6: Student engagement has a significant positive impact on teaching result

\subsection{Service learning teaching effect}

Service learning teaching effect refers to the final result caused by teaching mode of service learning. Despite the diversified measurement indexes, it is generally necessary to demonstrate the ultimate realization of service learning teaching objectives from observation perspective of students ${ }^{[12]}$. If students acquire less knowledge or have low satisfaction through teaching model of service learning, it indicates from another aspect that teaching result of service learning is unobvious. If students get quite rich experiences through service learning, it suggests that service learning has achieved the desired effect, so this paper makes measurement from the 
two aspects of students' satisfaction with service learning and improvement of student's ability.

\section{Data Sources and Research Design}

\subsection{Questionnaire design and data collection}

In this paper, the scale is designed based on Likert five-level measurement method. The questionnaire contains items of respondents' basic information, project resource quality, teaching organization quality, student engagement and teaching result. In order to ensure scale validity and reliability, the scale design refers to maturity scale of relevant research at home and abroad, and also considers major characteristics of ecommerce. A small-scale survey was organized first before the design, some of the items and statement expressions were modified according to the feedback. On this basis, questionnaires were distributed among students participating in e-commerce service learning in Nanjing, Zhenjiang, Yangzhou and Hangzhou. After a span of 11 days, 240 valid questionnaires were collected after deleting 52 incomplete questionnaires.

\subsection{Research design}

Structural Equation Modeling (SEM) is suitable for investigation and analysis of complex multivariate data. Capable of analyzing causal relationship between multiple variables at the same time, it is a powerful method for statistical analysis of data [13]. In the fields of pedagogy, psychology, marketing research, organizational behavior and economics, there are some hypothetical constructs that cannot be directly observed or directly measured (although their effects may be easily observed). The hypothetical construct is only an abstract concept that cannot be directly known, and it is often multivariant, so it is impossible to make effective analysis by traditional factor analysis or multiple regression analysis. Structural equation modeling, a statistical technique that integrates factor analysis and multiple variables for simultaneous regression analysis, can estimate and verify the various complex factors affecting the teaching result in service learning and the significance degree of influence of each factor. Since this paper is an exploratory study and the sample size is also small, model is built using SmartPLS3.0 to verify the hypotheses.

\section{$4 \quad$ Data Analysis and Results}

\subsection{Measurement model}

The measurement of pros and cons of the measurement model involves two perspectives of reliability and validity tests. Reliability can be tested by the combination of Composite Reliability and Cronbach's Alpha of variables. As shown 
in Table 1, the composite reliability values of the variables in this paper are all above 0.835, and Cronbach's Alpha are all above 0.745. According to the related literature ${ }^{[13]}$, composite reliability and Cronbach's Alpha above 0.7 sufficiently show high reliability of the measurement model.

Table 1. Table Confirmatory factor analysis

\begin{tabular}{|l|c|c|c|}
\hline & Composite Reliability & Cronbach's Alpha & AVE \\
\hline Project resource & 0.879 & 0.801 & 0.712 \\
\hline Teaching organization & 0.835 & 0.745 & 0.565 \\
\hline Student engagement & 0.884 & 0.827 & 0.656 \\
\hline Teaching result & 0.918 & 0.821 & 0.848 \\
\hline
\end{tabular}

AVE (Average Variance Extracted) in Table 1 is average extracted variance value. According to the related literature ${ }^{[14]}$, AVE greater than 0.5 indicates that the scale has good convergence validity. As can be seen from Table 1, AVE values are all above 0.5 , so it can be considered that the measurement model ideally meets convergence validity requirements. Discriminant validity is tested by comparing correlation between the square root of AVE value and latent variables of the model. It can be seen from Table 2 that correlation coefficient of all latent variables on the offdiagonal line is much smaller than the square root of AVE value on the diagonal line, which suggests high discriminant validity between latent variable and other latent variables.

Table 2. Discriminant validity analysis

\begin{tabular}{|l|c|c|c|c|}
\hline & Project resource & $\begin{array}{c}\text { Teaching } \\
\text { organization }\end{array}$ & Student engagement & Teaching result \\
\hline Project resource & 0.844 & & & \\
\hline $\begin{array}{l}\text { Teaching } \\
\text { organization }\end{array}$ & 0.291 & 0.752 & & \\
\hline Student engagement & 0.382 & 0.520 & 0.810 & \\
\hline Teaching result & 0.349 & 0.543 & 0.738 & 0.921 \\
\hline
\end{tabular}

\subsection{Structural equation model fitting}

In this paper, Partial Least Squares (PLS) structural equation software SmartPLS3.0 is used to analyze the structural equation model established herein and verify the proposed hypothesis. The results of path analysis are shown in Figure 1. The path coefficients reflect the relationship and influence degree of the latent variables in the model. The R2 value indicates the extent to which the endogenous latent variables are interpreted by the exogenous latent variables. In order to better measure validity of the model, GoF index is used to test goodness of fit of the model [13]. The value of GoF is 0.480 , which is much higher than the effective threshold of 0.36 , demonstrating good global goodness of fit of the model. 


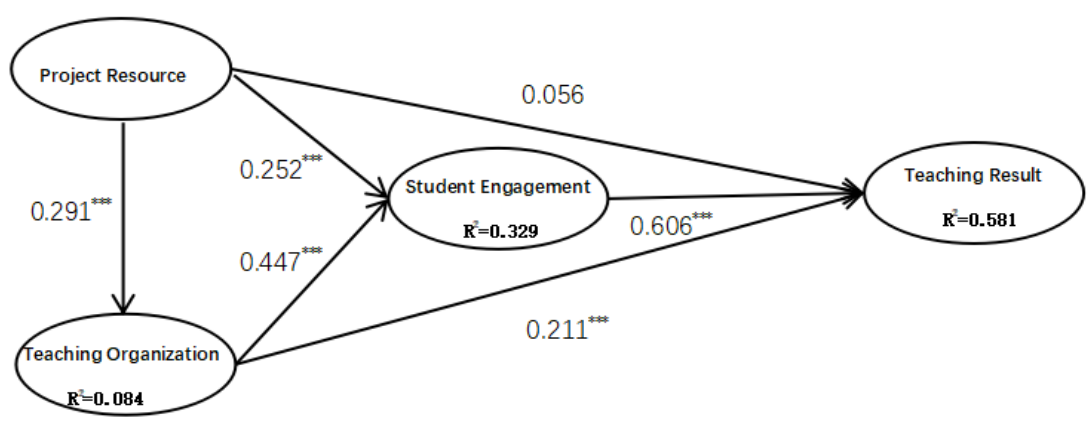

Fig. 1. Key variable path analysis

Note: *** indicates that $\mathrm{P}$ is less than $0.001,{ }^{* *}$ indicates that $\mathrm{P}$ is less than 0.01 , and * indicates that $\mathrm{P}$ is less than 0.05 .

The PLS path analysis demonstrates that project resource has a significant impact on teaching organization $(0.291, \mathrm{P}<0.001)$, and $\mathrm{H} 1$ is proved; project resource and teaching organization have a significant impact on student engagement $(0.252$, $\mathrm{P}<0.001 ; 0.447, \mathrm{P}<0.001), \mathrm{H} 2, \mathrm{H} 5$ are thus proved; project resource has insignificant impact on teaching result $(0.056, \mathrm{P}>0.05), \mathrm{H} 3$ is thus not supported; teaching organization has a significant impact on teaching result $(0.211, \mathrm{P}<0.001), \mathrm{H} 4$ is thus proved; student engagement has a significant impact on teaching organization $(0.606$, $\mathrm{P}<0.001$ ), and $\mathrm{H} 6$ is verified.

According to the recommendations in literature ${ }^{[21]}$, it is necessary to further analyze the mediating role of teaching organization and student engagement in the impact of teaching result. The traditional research method is to adopt Sobel test to study indirect effect, but Hayes believes that Sobel test is not suitable for the mediating effect test under partial least squares method ${ }^{[15,16]}$. Nitzl and Roldan methods are thus used instead to verify whether the mediating effect is significant by combining the parameters estimated by bootstrapping algorithm in PLS ${ }^{[17]}$. As shown in Table 3, T-value test shows that all path coefficients pass the significance test at the 0.001 level, and $95 \%$ interval is positive excluding 0 , which verifies that teaching organization plays an intermediary role in project resource and student engagement, so is student participation in project resource, teaching organization and teaching result.

Table 3. Mediating effect test on organization quality and student engagement

\begin{tabular}{|c|c|c|c|c|c|c|}
\hline \multirow[t]{2}{*}{ Indirect effect path } & \multirow{2}{*}{$\begin{array}{c}\text { Indirect effect } \\
\text { point estimation }\end{array}$} & \multicolumn{3}{|c|}{ Bootstrap 1000 times } & \multicolumn{2}{|c|}{$\begin{array}{c}95 \% \text { confidence } \\
\text { interval }\end{array}$} \\
\hline & & $S E$ & $T$ & $P$ & low & upper \\
\hline $\begin{array}{l}\text { Project Resource- }>\text { Teaching } \\
\text { Organization- }>\text { Student Engagement }\end{array}$ & 0.130 & 0.035 & 3.754 & $<0.001$ & 0.070 & 0.210 \\
\hline $\begin{array}{l}\text { Project Resource-> Student } \\
\text { Engagement }->\text { Teaching Result } \\
\end{array}$ & 0.153 & 0.039 & 3.933 & $<0.001$ & 0.078 & 0.231 \\
\hline $\begin{array}{l}\text { Teaching Organization-> Student } \\
\text { Engagement -> Teaching Result }\end{array}$ & 0.271 & 0.039 & 6.935 & $<0.001$ & 0.198 & 0.350 \\
\hline
\end{tabular}


This indicates that the influence of each latent variable on teaching result is a result of combined action of direct influence and indirect influence. The total influence coefficient can be determined by calculating the sum of direct influence coefficient and indirect influence coefficient, as shown in Table 4.

Table 4. Total effect

\begin{tabular}{|l|c|c|c|}
\hline & Teaching Organization & Student Engagement & Teaching Result \\
\hline Project Resource & 0.291 & 0.382 & 0.349 \\
\hline Teaching Organization & & 0.447 & 0.482 \\
\hline Student Engagement & & & 0.606 \\
\hline
\end{tabular}

From the results of Figure 3, Table 4 and mediating effect significance test, project resource, teaching organization and student engagement have a significant impact on service learning teaching result. Among them, student engagement factor has the greatest impact on service learning teaching result (0.464). In addition to the direct influence on teaching result, teaching organization indirectly affects the final teaching result through the influence on student engagement. The influence of project resource on teaching result is indirect, that is, indirectly affecting teaching result through the influence on teaching organization and student engagement. This shows that for each higher standard deviation of project resource, teaching organization and student engagement, service learning teaching result will increase by $0.349,0.482$ and 0.606 standard deviations respectively.

\section{$5 \quad$ Suggestions for Improving Teaching Result of Service Learning}

\subsection{Strengthen service education base and project construction}

Seen from the research results, project resource quality does not have a direct impact on service learning teaching result, but it has a certain indirect effect through teaching organization and student engagement. Project implementation represents an important link in service learning cultivation. Faced with some constraints and limitations in service learning base and project construction process, school should strengthen construction measures, and explore diversified service learning base operation modes. On the basis of construction of service learning platform inside and outside the school, it is necessary to seek appropriate project source based on project and subject characteristics. In this process, a "win-win" thinking mode should be created with the source subject, which will help the project subject solve the problem on the one hand, and facilitate school curriculum learning on the other hand. For example, in the construction of e-commerce service learning platform, we allow students to participate in government-sponsored e-commerce poverty alleviation projects, so that students can have a platform for learning while making contribution to society. On this basis, service learning teaching system supported by multi-level courses should be established. 


\subsection{Strengthen teaching process management and teaching organization design}

According to the workflow of e-commerce project, the project workflow is further subdivided into three sub-processes: service learning preparation process, service learning operation process, service learning reflection and conclusion process, and specific learning objectives are assigned to students in each sub-process. In the service learning organization design, overall arrangements should be made for the entire service learning curriculum, plans and specific programs should be made, including establishment of service learning group, operation plan design, and specific implementation of the plan. In the service learning process, the tasks of service learning project teams should be evaluated and monitored in time to ensure that subgoals of teaching are completed in all aspects. In the design of teaching function completed by service learning project, it is necessary to comprehensively apply and implement various aspects and key contents of the curriculum within the training program to ensure realization of its teaching function.

\subsection{Guide students correctly and improve students' enthusiasm for participation}

In service learning project practice, many students often take a sloppy attitude towards specific work, failing to reflect the spirit of dedication in specific matters. From the above research, it can be seen that in the project practice teaching of service learning, how to improve enthusiasm of students to participate in service learning projects is a key point. Service learning instructors should play a role in diversifying incentives, using a variety of incentives to stimulate students' participation enthusiasm, so that students are willing to do service projects. It is necessary to strive to start service learning and practice teaching activities and continuously improve the pertinence and practicality, arrange project rhythm according to students' learning characteristics, improve the coaching and monitoring mode of teachers in the process, let students experience joy of learning in service learning, so that they can continuously ensure high efficiency input into and participation enthusiasm for service learning for a long time.

\section{Research Deficiencies and Research Prospects}

It should be pointed out that there are many factors in the various aspects of service learning that exert different influences. The existing literature indicates that the main influencing factors include satisfaction with service learning, social contribution, school support, teacher guidance, student knowledge system, total extra-curricular service time of students and team cohesion, etc. ${ }^{[7][10]}$. In this study, the main considerations are given to resource conditions of the service project, education end organizational design and student engagement. This can only serve as a preliminary study which plays a role in starting discussions. In the future service learning study of 
e-commerce professional course, we should fully consider complexity of internal and external conditions, reasonably consider the mechanism of action of different factors on students' knowledge application and skills formation in service learning, so that service learning teaching can achieve the preset teaching objectives ${ }^{[1]}$.

\section{$7 \quad$ References}

[1] Sternberger L G, Ford K A \& Hale D C. International service learning: Integrating academics and active learning in the world [J].Journal of Public Affairs. 2005(8):75-96.

[2] James K. Elmborg, Heather Leighton, Holly Huffman. Service learning in the library and information science curriculum [J].Research Strategies. 2001(18):265-281.

[3] GregoryJ. Service learning, multiculturalism and the pedagogies of difference [J].Pedagogy.2008, 8(2), 255-281. https://doi.org/10.1215/15314200-2007-040

[4] LI Chuan, LI Lingling. An Empirical Study of the Influence of Service Learning on College Students' Autonomous Learning Ability[J].Journal of Guangdong University of Foreign Studies,2015,26(06): 100-104.

[5] Guan Xuan. Experience and reflection of "service learning" in public universities in Hong Kong [J]. Higher Education Exploration, 2017 (04): 65-69.

[6] Zhang Lijun. Exploration into Practice Teaching Reform of "Social Work in the Aged" Based on Service Learning [J]. Higher Education Forum, 2018(05): 30-32+55.

[7] Jerusha OConner. Learning to unlearn: How a service-learning project can help teacher candidates to reframe urban students[J]. Teaching and Teacher Education. 2010 (26): 1170-1177.

[8] Currie-MuellerJL, Littlefield RS.Embracing service-learning opportunities: student perceptions of service-learning as an aid to effectively learn course material[J].Journal of the Scholarship of Teaching and Learning, 2018,18(1):25-42. https://doi.org/ 10.14434/josotl.v18i1.21356

[9] RickeA.Finding the right fit: helping students apply theory to service-learning contexts[J].Journal of Experiential Education, 2018, 41(1):8-22. https://doi.org/ $\underline{10.1177 / 1053825917750407}$

[10] Eyler J.Reflecting on service: Helping nursing students get the most from servicelearning[J].J Nurs Educ.2002,41(10):453-456.

[11] GerholzK,Liszt, V; KlingsieckK B.Effects of learning design patterns in service learning courses[J].Active Learning in Higher Education.2018,19(1):47-59. https://doi.org/10.1177/1469787417721420

[12] Mergler CarringtonS, KimberMP.Exploring the value of service-learning on preservice teachers[J].Australian Journal of Teacher Education, 2017, 42(6):69-80. https://doi.org/ 10.14221/ajte.2017v42n6.5

[13] Joseph F. Hair JR, Tomas M Hult. Structural Equation Modeling - Partial Least Squares Method PLS-SEM [M]. Higher Education Culture Enterprise Co., Ltd. Taipei, China, 2016.

[14] Zhou Yu, Zhong Weijun, Mei Shue. Research on the Mechanism of Enterprise Agility Improvement by Information System [J]. Science of Science and Management of S.\&.T., 2015(7): 70-83.

[15] Hayes A F.Beyond baron and kenny: statistical mediation analysis in the new millennium[J]. Communication Monographs 2009, 76 (4):408-420. https://doi.org/ $\underline{10.1080 / 03637750903310360}$ 
[16] Hayes A F and Scharkow M. The relative trustworthiness of inferential test of the indirect effect in statistical mediation analysis: does method rally matter? [J]. Psychological Science, 2013, 24(10):1918-1927. https://doi.org/10.1 $177 / 0956797613480187$

[17] [17]Nitzl C,Roldan J L.,Cepeda G.Mediation analysis in partial least squares path modeling[J].Industrial Management \& Data Systems.2016, 116(9):1849-1864. https://doi.org/10.1108/IMDS-07-2015-0302

\section{Authors}

Jie Ji is a lecturer of education in School of Textile \& Clothing at Yangzhou Polytechnic College, his research interests including services learning and deep learning. Email id: 0104013@yzpc.edu.cn

Jianqiang Gu is a lecturer and postgraduate students' tutor in Business School at Yangzhou University, his research interests including services learning, e-businesses and information security. Email id: gujianqiang@yzu.edu.cn

Article submitted 2019-01-17. Resubmitted 2019-03-16. Final acceptance 2019-03-26. Final version published as submitted by the authors. 